Pakistan Journal of Education Vol.36, No.3, 2019, 211-225

\title{
Predictive Value of Academic Anxiety for Academic Achievement of University Students
}

\author{
Maliha Nasir ${ }^{*}$ \\ Amir Zaman ${ }^{* *}$
}

\begin{abstract}
Academic anxiety is a well-known concept. Usually when students transit from one institution to another, they have both positive and negative feelings. The uncertainty of a new academic environment may provoke anxious feelings. These feelings may affect student's academic achievement. This research paper intended to investigate whether or not academic anxiety and academic achievement of university students are related. Also, the predictability of academic anxiety for academic achievement was intended to be measured. A survey was conducted on 150 students who were enrolled in the first semester of Pre-service teacher training programs in the Institute of Education, University of Azad Jammu and Kashmir. Data was collected through Academic Anxiety Questionnaire. It was found that academic anxiety significantly correlates with academic achievement of the students and the correlation is negative. Students having low scores on academic anxiety showed better results than the students with high scores on academic anxiety. It was also found that academic anxiety significantly predicts academic achievement and its behavioural and physiological components accounted for significant variance.
\end{abstract}

Keywords: academic anxiety, behavioural component, cognitive component, physiological component, emotional component, academic achievement.

\footnotetext{
* Assistant Professor, Institute of Education, University of Azad Jammu and Kashmir. Email:malihanasir@hotmail.com

** Assistant Professor, Department of Education, Abdul Wali Khan University, Mardan
} 


\section{Introduction}

In the competitive world of today students face many problems to cope with the challenges of their academic endeavors. The race of best academic performance, high merit for admission in prestigious educational institutions and need of high qualification and merit for recruitment in respected job positions have put students in a state of mental burden. Sometimes, these factors lead to severe psychological conditions like anxiety and depression. Anxiety, especially, is a common problem among students. It is the feeling of uneasiness produced in the wake of uncertainty. Students, generally, feel anxious when they enter in a new institution or register in a difficult course. Examinations and tests also cause anxiety. Students' inability to adopt effective study habits may also be a reason of anxiety.

Anxiety, usually, results in poor performance due to lack of concentration, nervousness and failure to adopt appropriate course of action. An individual may feel anxious in different situations which he/she may consider difficult, uncertain or challenging. For example, a speaker may get anxious in front of a large audience, a child get anxious on the very first day of school, a student get anxious on the day of an important exam, etc. Similarly, the challenging academic situations provoke anxious feelings in students.

When students enter in an institution of higher education, they face new environment, challenging academic tasks and independent working. These experiences produce positive feelings like pleasure and excitement as well as negative emotions like anxiety and weariness. These emotional states may affect their academic performance either positively or negatively. The institutions of higher education prepare students for entering in the practical life. There is a need to assess the extent to which academic anxiety interfere in the academic achievement of students, so that, appropriate measure may be taken to save students from the negative effects of academic anxiety. This study may be helpful in understanding various components of anxiety that may obstruct the academic performance of university students.

\section{Literature Review}

Anxiety is a feeling of uneasiness in an uncertain condition. Anxiety is associated with negative thoughts and feelings. According to American Psychiatric Association (2013) anxiety is state of "tension and vigilance in preparation of future danger" (p.43). Shakir (2014) considers anxiety as "one 
of the most widely experienced emotion" and "essential construct of human behaviour" (p.29).It is an instinctive reaction to challenging situations. When these challenging situations are associated with academic matters, the resulting uneasiness may be referred to as academic anxiety.

Khemka (2016) relates academic anxiety to the fear of any upcoming risk from the educational settings which may include teachers and some difficult subjects. Shakir (2014) explains academic anxiety as "a mental feeling of uneasiness or distress in reaction to a school situation that is perceived negatively" (p. 29). These negative feelings not only affect the daily routine tasks but also academic achievement of students (Azeem, 2018).

Academic anxiety may arise from different source. Students having Trait Anxiety show anxious behaviour most of the time (Horikawa and Yagi, 2012). Previous educational record may provoke anxiety because students who showed poor performance in the past may feel anxiety about level of their future performance and good record keepers may be anxious to show same or even better performance. Other factors like time constraints, teachers' attitude and behaviour, task difficulty and complexity, etc. may also provoke anxious feelings in students (AAAC, nd) and these feelings may result in problems like inability to concentrate, difficulty in recalling information or poorly performing a task (Alam, 2017; Shahrouri, 2016).

Shahrouri (2016) identified sources of academic anxiety which included: i) study anxiety, i.e. anxious feelings during study; ii) foreign language anxiety, i.e. feeling of nervousness while using a second language; iii) social anxiety, i.e. hesitation in interaction with others and fear of being wrongly judged; iv) emotional anxiety, i.e. producing negative feelings and emotions and v) Parental expectations, i.e. pressure from parents for good performance. Vitasari, Abdul Wahab, Othman and Awang (2010) also identifies similar sources with addition of classroom presentation anxiety and mathematic anxiety.

According to Vye, Welch \& Kathlene (2007), three interrelated elements constitute anxiety. These include 1) cognitive aspect, 2) physiological aspect and 3) behavioural aspect. Our perception and interpretation of our environment is the cognitive part of anxiety and it is usually in the form of negative attitude and thinking. Physiological aspect of anxiety is related to physical changes that take place during an anxiety provoking situation, e.g. increase in pulse rate, wet palms, headache, etc. Whatever actions a person takes in an anxious situation make the behavioural part of anxiety. A fourth component is also associated with anxiety which 
involves emotional conditions in anxiety provoking situations, e.g. fear, sadness, anger, panic, etc. (Richard, 2016 and Dorter, nd).

Research literature includes many studies in which a negative correlation has been examined between academic anxiety and academic achievement. Azeem (2018) studied 340 students at secondary level in Aligarh and found that academic anxiety and academic achievement were negatively correlated. Sharma and Pandey (2017) found that anxiety influenced the academic performance when they studied 120 students in $11^{\text {th }}$ grade in the rural area of Chhattisgarh state. Shakir (2014) found negative correlation between academic achievement and academic anxiety. He also found significant difference in academic achievement of students with high anxiety and low anxiety level. Nasir and Iqbal (2012) presented a conference paper concluding that new environment of academic institution provokes anxiety which in turns negatively affects academic achievement.

Other studies also found similar results, for example, Vitasari, Abdul Wahab, Othman, Herawan, and Sinnadurai, (2010) found negative correlation between study anxiety and academic performance of engineering students; Rana and Mahmood (2010) concluded that test anxiety negatively affects academic performance of post graduate students and Chapell, et.al. (2005) found relationship between test anxiety and academic performance of undergraduate and graduate students.

There are some studies which contradict to this notion. For example, Al-Qaisy (2011) found a positive correlation between trait anxiety and academic achievement in a study of 200 university students. The results of the study indicated that medium level of concern results in better performance. Students who are anxious about their performance try to work hard resulting in better performance. Bisson (2017) studied effect of anxiety and depression on academic performance of college students and found no significant correlation between anxiety and academic performance. In the study of Ibrahim (nd) it was found that students were more anxious when they started the academic session than at the end of session.

Research shows that anxiety produces a hidden cost that may not be apparent in performance however, it affects the amount of effort taken to perform a task (ESRC, 2009).Generally it is perceived that anxiety is a negative element but it also serves as a motivating factor. Mild anxiety has positive effect on performance as it focuses attention on a specific task; however, intense anxiety may have negative effects (Yahaya, nd). 
Yen et.al. (2007) studied correlation between Academic achievement and anxiety and concluded that global anxiety had no significant correlation with academic performance, however, when the sample was divided into groups of low, moderate and high anxiety, there was both positive and negative correlation. Very high and very low anxiety results in poor performance while moderate anxiety results in better performance. Alam (2017) also concluded that moderately anxious students perform well as compared to those having high anxiety or very low anxiety.

The above stated research shows that high academic anxiety may have adverse effects on academic performance of students; however its absence or low level may also results in poor academic performance. The arguments given above, led the researchers towards the conceptualization of this research paper. This research paper intends to find out whether academic anxiety affects the performance of students in pre-service teacher training programs. The major objective was to examine any relationship between academic anxiety and academic achievement of students in pre-service teacher training programs. The research paper also intended to find out the predictability of academic anxiety for academic achievement of these students.

The null hypothesis for the study was

$\mathrm{H}_{\mathrm{o}}$ : There is no relationship between academic anxiety and academic achievement.

The alternate hypothesis proposed in the light of literature review was

$\mathrm{H}_{1}$ : There is a relationship between academic anxiety and academic achievement.

It was also hypothesized that

$\mathrm{H}_{2}$ : Academic anxiety may predict academic achievement.

The significance level for hypothesis testing was set at 0.05 .

The methodology adopted to test the hypothesis is given in the next section.

\section{Methodology}

Quantitative research design was adopted for this study. A survey was conducted to collect data and the obtained data was analyzed by applying suitable quantitative statistics. 


\section{Sample}

Participants of the study were 150 students enrolled in preservice teacher training programs in the Institute of Education, University of Azad Jammu and Kashmir. Three classes were conveniently selected in which the researcher was teaching.

\section{Instrument}

A questionnaire was developed to measure academic anxiety. The questionnaire was adapted from Academic Anxiety Questionnaire of Academic Achievement and Access Center of the University of Kansas (AAAC, nd). A few statement were selected from the questionnaire and some new statements were added as needed for collecting required information. The total number of statements in the questionnaire was 20.These statements described the Physiological, cognitive, emotional and behavioral components of anxiety and were responded as true or false.

The scores on four components were significantly correlated with each other and with the overall score indicating construct validity of the instrument (Table 1).

Table 1

Coefficients of Correlation of Four Components with Academic Anxiety. $($ Items $=20)(N=150)$

\begin{tabular}{lccccc}
\hline & Behavioural & Cognitive & Emotional & Physiological & Anxiety \\
\hline Behavioural & - & & & & \\
Cognitive & $273^{* *}$ & - & & & \\
Emotional & $290^{* *}$ & $259^{* *}$ & - & & \\
Physiological & $391^{* *}$ & $268^{* *}$ & $285^{* *}$ & - & \\
Anxiety & $501^{* *}$ & $716^{* *}$ & $622^{* *}$ & $685^{* *}$ & - \\
\hline$* 0.01$ & & & &
\end{tabular}

Cronbach alpha was calculated for the reliability estimate of the research tool. The value of alpha coefficient (.71) indicated that the instrument has internal consistency.

\section{Data Collection and Analysis}

For collection of data the questionnaire was administered in classroom setting. Students were given the questionnaires to be filled. The time require to fill the questionnaire wasapproximately10-15 minutes. 
Quantitative techniques were applied for data analysis. The relationship between variables was determined through calculating Pearson Product Moment Coefficient of Correlation and the predictability of academic anxiety for academic achievement was determined through regression analysis. The difference in the academic achievement of low and high anxiety groups was confirmed by applying t-test.

\section{Results}

The correlation analysis revealed a significant negative correlation $(\mathrm{r}=-.329, \mathrm{p}<.01)$ between academic anxiety and academic achievement (Table 2). Out of four components of anxiety, three components behavioural $(\mathrm{r}=-.403, \mathrm{p}<.01)$, cognitive $(\mathrm{r}=-.202, \mathrm{p}<.05)$ and physiological $(\mathrm{r}=-.304, \mathrm{p}<.01)$ have significant negative correlation with academic achievement. Emotional component did not show significant correlation $(r=-.109, \mathrm{p}>.05)$.

Table 2

Coefficients of Correlation of Academic Anxiety and its Components with Academic Achievement. $(N=150)$

\begin{tabular}{lcc}
\hline & Pearson $\mathrm{r}$ & Significance level \\
\hline Academic Anxiety & -.329 & .000 \\
Behavioural & -.403 & .000 \\
Cognitive & -.202 & .013 \\
Emotional & -.109 & .186 \\
Physiological & -.304 & .000 \\
\hline
\end{tabular}

Two groups, i.e. high anxiety group and low anxiety group, were identified by dividing the sample at the cut point of their mean scores. Those having anxiety scores above the mean score were identified as high anxiety group while those having score lower than mean were identified as low anxiety group. Difference in the academic achievement of these two groups was determined through t-test. 
Table 3

Comparison of Mean GPA of Students with High and Low Score on Academic Anxiety and its Four Components. $(N=150)$

\begin{tabular}{lccccc}
\hline Variables & Group (N) & $\begin{array}{c}\text { Mean } \\
\text { GPA }\end{array}$ & $\begin{array}{c}\text { Standard } \\
\text { Deviation }\end{array}$ & $\begin{array}{c}\text { Standard } \\
\text { Error Mean }\end{array}$ & t-values \\
\hline Academic & High (82) & 2.24 & .383 & .046 & $-2.148^{*}$ \\
Anxiety & Low (68) & 2.37 & .379 & .042 & \\
Behavioural & High (76) & 2.18 & .362 & .042 & $-4.240^{* *}$ \\
& Low (74) & 2.44 & .368 & .043 & \\
Cognitive & High (64) & 2.28 & 16.076 & .379 & -.758 \\
& Low (86) & 2.33 & 14.944 & .390 & \\
Physiological & High (60) & 2.16 & .362 & .047 & $-3.950^{* *}$ \\
& Low (90) & 2.41 & .371 & .039 & \\
Emotional & High (84) & 2.28 & .345 & .038 & -1.176 \\
& Low (66) & 2.35 & .429 & .053 & \\
\hline$*$
\end{tabular}

${ }^{*} \mathrm{p}<0.05,{ }^{* *} \mathrm{p}<0.01$

The group with high academic anxiety secured significantly lower GPA than the group with low anxiety $(\mathrm{t}=-2.148, \mathrm{P}<.05$; Table $3)$.However, only two components i.e., Behavioural $(t=-4.240, P<.01)$ and Physiological $(\mathrm{t}=-3.950, \mathrm{P}<.01)$ components significantly differentiate the GPA of high and low groups(Table 3). These results show that the null hypothesis may be rejected and alternate hypothesis may be accepted.

The predictive value of academic anxiety was determined by regression analysis. The four components of academic anxiety were entered as independent variables and academic achievement as dependent variable. A significant correlation of academic achievement was found with four components in a combination. 
Table 4

Model Summary of Regression Analysis for Four Components of Academic Anxiety Predicting Academic Achievement. $(N=150)$

\begin{tabular}{llccccc}
\hline Criterion & Predictors & $\mathrm{R}$ & $\mathrm{R}^{2}$ & $\begin{array}{c}\text { Adjusted } \\
\mathrm{R}^{2}\end{array}$ & $\begin{array}{c}\text { Std. Error } \\
\text { of the } \\
\text { Estimate }\end{array}$ & $\mathrm{F}$ \\
\hline GPA & $\begin{array}{l}\text { Behavioural, Cognitive, } \\
\text { Physiological, } \\
\text { Emotional }\end{array}$ & .441 & .195 & .172 & .350 & $8.760^{* *}$ \\
& & & & & & \\
\hline $\mathrm{p}<.01$ & & & & & &
\end{tabular}

Model summary of regression analysis (Table 4) indicates that the combination of four components was significantly related to academic achievement $(\mathrm{R}=.441, F(4,145)=8.760, p<.01)$. The value of adjusted $\mathrm{R}^{2}$ shows that these components accounted for $17 \%$ variance in academic achievement as measured by GPA $\left(\mathrm{R}^{2}=.172\right)$.

The relative significance of four components of academic anxiety for predicting academic achievement is given in table 5. Only two components Behavioural $(t=-3.954, p<.01)$ and Physiological $(t=2.018$, $p<.05)$ showed significance for predicting academic achievement. Cognitive and Emotional component were not significant at .05 level.

Table 5

Relative Significance of the four Components of Academic Anxiety in Predicting Academic Achievement. $(N=150)$

\begin{tabular}{llcccc}
\hline Criterion & Predictors & $\mathrm{B}$ & Standard Error & Beta & $\mathrm{t}$ \\
\hline GPA & (Constant) & 2.827 & .098 & & $28.902^{* *}$ \\
& Behavioural & -.118 & .030 & -.331 & $-3.954^{* *}$ \\
& Cognitive & -.025 & .025 & -.081 & -1.011 \\
& Emotional & .018 & .026 & .056 & .698 \\
& Physiological & .059 & .029 & -.169 & $-2.018^{*}$ \\
\hline
\end{tabular}

p $<.05,{ }^{* *} \mathrm{p}<.01$

In order to determine the predictability of each component of academic anxiety for academic achievement, stepwise regression analysis was run (Table 6). 
Table 6

Stepwise Regression for Components of Academic Anxiety Predicting Academic Achievement. $(N=150)$

\begin{tabular}{lllll}
\hline Criterion & \multicolumn{1}{c}{ Variables } & B & SE & $\beta$ \\
\hline GPA & $\begin{array}{l}\text { Step 1 } \\
\text { (Constant) }\end{array}$ & 2.809 & .098 & \\
& $\begin{array}{l}\text { Behavioural } \\
\text { Step 2 }\end{array}$ & -.144 & .027 & $-.403^{* *}$ \\
& & & \\
& (Constant) & 2.813 & .097 & \\
& Behavioural, & -.120 & .029 & $-.335^{* *}$ \\
& Physiological & -.060 & .028 & $-.173^{*}$ \\
\hline
\end{tabular}

Note: $\mathrm{R}^{2}=.156(p<.01)$ for Step $1 ; \Delta \mathrm{R}^{2}=.020$ for Step $2(p<.01)$. p $<.05,{ }^{* *} \mathrm{p}<.01$

The behavioural component of academic anxiety entered at the first step of regression analysis showing its best predictive value for academic achievement. This component accounted for $15.6 \%$ variance in GPA $\left(\mathrm{R}^{2}=.156, p<.01\right)$. In the next step physiological component added $2 \%$ in the variance $\left(\mathrm{R}^{2}=.176, p<.01 ; \Delta \mathrm{R}^{2}=.020\right)$. The other two components did not significantly contribute in the variance. Therefore, following regression equation can be used to predict GPA of university students on the basis of academic anxiety.

$\mathrm{GPA}=-.120 \times$ Behavioural $+-.060 \times$ Physiological +2.813

On the basis of these results the hypothesis that academic anxiety may predict academic achievement, may be accepted.

\section{Discussion}

The results of this study indicated that academic anxiety is one of the significant predictors of academic achievement. A negative relationship was found between academic anxiety and academic achievement of students studying in pre-service teacher training programs. The academic achievement was poor where anxiety level was high and better results were shown where anxiety level was low. Previous research also revealed the same phenomenon. For example, Azeem, 2018; Sharma and Panday, 2017; Shakir (2014); Nasir and Iqbal, 2012; etc. found negative correlation between academic anxiety and academic performance.

Those individuals who are more prone to get anxious in difficult or uncertain situations get easily distracted resulting in reduced concentration which in turn hinders learning and affects academic performance (Afolayan, Donald, Onasoga, Babafemi and Juan, 2013). As 
anxiety produces a hidden cost in performance (ESRC, 2009) the more anxious students have to put more effort to show performance at equivalent level with less anxious students (Afolayan, Donald, Onasoga, Babafemi and Juan, 2013).

A significant difference was found in the GPA of students with high level of anxiety and those with low level of anxiety. Students with low anxiety showed better results. This finding corresponds to the finding of Vitasari, Abdul Wahab, Othman, Herawan, and Sinnadurai, (2010) Rana and Mahmood (2010) and Chapell (2005).It was also confirmed that a significant difference is present in the academic achievement of the students who scored higher on behavioral and physiological components of academic anxiety and those who scored low. These two component significantly predict academic achievement. Behavioural component includes the actions of an individual in an anxiety provoking situation, for example, being nervous, unable to concentrate, etc.; and physiological components include physical reactions of body when situation becomes anxiety provoking, for example, tight stomach, wet palms, fast heartbeat, etc.

Khemka (2016) argues that the physiological conditions of an anxious person may distract him/her from the task at hand making the task difficult. A person with fast heartbeat, tight stomach or other physical symptoms of anxiety cannot concentrate on the task. This lack of concentration results in poor performance.

Similarly, the behavioural actions in an anxiety provoking situation, for example, avoidance or nervousness may result in poor performance. When an individual choose to avoid a difficult situation rather than face it, the result is usually failure. Persons having high level of anxiety face difficulty in avoiding distractions, thus, reducing their level of attention for switching from one task to the next (Afolayan, Donald, Onasoga, Babafemi, Juan, 2013). Otten (1991) also asserts that academic tasks may be negatively affected due to behavioural reactions of students in an anxiety provoking situation.

Academic anxiety is generally produced in new unpredictable situations like taking admission in a new course and it may affect academic performance of students as this factor significantly predict the academic performance. Students having severe conditions of anxiety may even drop the course in which they cannot cope with anxious feelings. Therefore, appropriate attention should be given to the phenomenon so that student can complete their educational work. 


\section{Conclusion and Recommendations}

The study concludes that academic anxiety is a significant predictor of academic achievement. It has negative correlation with academic achievement which means that increased academic anxiety results in decreased level of performance. Out of four components of anxiety, two components significantly predict academic achievement. The behaviours that students show during anxiety provoking situations and the physiological reactions of body affect their performance. This is not the negative thoughts (cognitive component) or feelings (emotional component) that affect academic performance but the actions students take (behavioural component) and bodily reactions they face (physiological component) that determine their level of performance. Students performance is negatively affected when they fail to adopt an appropriate course of action, let themselves to distractions or face reflexive physiological reactions in anxiety provoking situations.

Therefore, it is advisable to address the problem of anxiety by providing appropriate guidance to students for adopting best course of action for coping with anxiety. As students feel more anxious in the beginning of an academic session, teachers may consider to design such academic activities which are not burdening for students. Examinations and tests also cause anxiety in students, therefore, teachers may guide students in adopting best approaches for exam preparation before examination time. Institutes of higher education may appoint counsellors for addressing psychological well-being of students. Teachers and senior students may be helpful in reducing the adverse effects of anxiety by extending supportive hands toward new students. 


\section{References}

Academic Achievement and Access Center (AAAC) Kansas University (nd).Academic Anxiety Questionnaire. Retrieved September 15, 2018, from

http://www2test.ku.edu/ achieve/guides/documents/academic_anxiet y_sources.pdf

Afolayan, J. A., Donald, B., Onasoga, O., Babafemi, A. and Juan, A. (2013) Relationship between anxiety and academic performance of nursing students, Niger Delta University, Bayelsa State, Nigeria, Advances in Applied Science Research, 4(5), 25-33

Alam, M. J. F. (2017) Relation between academic anxiety and academic achievement among school students of Murshidabad District, IJARIIE, 3(3), 3354-3357

Al-Qaisy, L. M. (2011). The relation of depression and anxiety in academic achievement among group of university students. International Journal of Psychology and Counseling, 3(5), 96-100

American Psychiatric Association (2013).Diagnostic and Statistical Manual of Mental Disorders ( $5^{\text {th }}$ Ed), Washington DC.

Azeem, M. A. (2018) Study of academic anxiety and academic achievement among secondary school students, International Journal of Research in Social Sciences, 8(3), 147-161

Bisson, K. H. (2017) The Effect of Anxiety and Depression on College Students' Academic Performance: Exploring Social Support as a Moderator, Digital Commons @ ACU, Electronic Theses and Dissertations Paper 51.

Chapell, M. S., et al. (2005). Test anxiety and academic performance in undergraduate and graduate students. Journal of Educational Psychology, 97(2), 268-274. DOI: 10.1037/0022-0663.97.2.268

Dorter, G.(nd) The Four Components of Anxiety, Retrieved October, 23, 2018 from https://www.guelphtherapist.ca/blog/four-components-ofanxiety/ 
Economic and Social Research Council (ESRC) (2009). Anxiety's hidden cost in academic performance. Science Daily. Retrieved July 15,2012 , from

http://www.sciencedaily.com/releases/2009/06/090623090713.htm Horikawa, M. and Yagi, A. (2012).The relationships among trait anxiety, state anxiety and the goal performance of penalty shoot-out by university soccer players, PLoS One. 2012; 7(4): e35727. Published online 2012 Apr 23. doi: [10.1371/journal.pone.0035727]

Ibrahim, A. I. (nd). Changes in level of anxiety and academic performance of college students. Retrieved July 15, 2018, from http://unilorin.edu.ng/journals/education/ije/sept1998/CHANGES\%2 0IN\%20LEVEL\%20OF\%20ANXIETY\%20AND\%20ACADEMIC \%20PERFORMANCE\%20OF\%20COLLEGE\%20STUDENTS.pdf

Khemka (2016) A study of academic anxiety of secondary school students, Techno LEARN, 6(1), p. 31-34, Retrieved July 15, 2018, fromhttps://ndpublisher.in/admin/issues/tlV6N1e.pdf

Nasir, M. and Iqbal, S. (2012) Relationship between academic anxiety and academic achievement of university students. Paper presented in 2nd Post Graduate Students Conference, November 29, 2012. Institute of Education and Research, University of the Punjab, Lahore.

Otten, A. J. (1991). Coping with academic anxiety. New York: Rosen Publishing Group.

Rana, R. A \& Mahmood, N. (2010). The Relationship between Test Anxiety and Academic Achievement. Bulletin of Education and Research December, 32(2), 63-74

Richard, J.(2016) The 4 Components of Anxiety, Retrieved October, 23, 2018 from http://positivestepscounseling.com/the-4-components-ofanxiety/

Shakir, M. (2014)Academic Anxiety as a Correlate of Academic Achievement, Journal of Education and Practice, 5(10), 2936citeseerx.ist.psu.edu/viewdoc/download?doi $=10.1 .1 .840 .7365$ 
Sharma, G. and Pandey, D. (2017) Anxiety, depression, and stress in relation to academic achievement among higher secondary school students, The International Journal of Indian Psychology, 4(2), 8289,DIP:18.01.051/20170402,DOI: 10.25215/0402.051

Shahrouri, E. A. (2016) Sources of academic anxiety among undergraduate students contemporary study between private and government universities, Journal of Emerging Trends in Educational Research and Policy Studies, 7(2), 118-124

Vitasari, P., AbdulWahab, M. N., Othman, A. and Awang, M. G. (2010) A research for identifying study anxiety sources among university students, International Education Studies, 3(2), 189-196

Vitasari, P., Abdul Wahab, M. N., Othman, A., Herawan, T. and Sinnadurai, S. K. (2010).The relationship between study anxiety and academic performance among engineering students. Paper presented at the International Conference on Mathematics Education Research. Retrieved July 15, 2018, from http://www.sciencedirect.com/science/article/pii/S1877042810021725 Vye, C., Welch, I. D. \&Kathlene, S. (2007) Under pressure and overwhelmed: coping with anxiety in college. USA, Greenwood Publishing Group.

Yahaya, A. H. (nd). Factors contributing towards excellence academic performance. Retrieved July 15, 2018, from http://eprints.utm.my/6109/1/aziziyahFactorscontributingtoe.pdf

Yen, Y. C. et. al. (2007) Correlations between academic achievement and anxiety and depression in medical students experiencing integrated curriculum reform, Kaohsiung Journal of Medical Science, 23(8), 379-385

\section{Citation of this Article:}

Nasir, M., Zaman, A. (2019). Predictive value of academic anxiety for academic achievement of university students. Pakistan Journal of Education, 36(3), 211-225

DOI: $10.30971 /$ pje.v36i3.672.g205

To link this article: http://dx.doi.org/10.30971/pje.v36i3.672 